\title{
Differences Influence Of Ladder Drill Scissor Hops And Icky Shuffle Training On Improvements Prosperity And Speed In Pencak Silat Athletes
}

\author{
Rojil Ghufron $^{1)}$, Adi Sucipto ${ }^{2)}$, Susilo Bekti ${ }^{3)}$ \\ ${ }^{1,2,3}$ Pendidikan Olahraga Pascasarjana \\ IKIP Budi Utomo Malang, Jawa Timur Indonesia \\ Email: ${ }^{1}$ Rojilghufron25@gmail.com, ${ }^{3}$ adis123.com@gmail.com, \\ ${ }^{3}$ susilobekti2006@gmail.com
}

\begin{abstract}
The purpose of this study was to analyze effect of ladder drill scissor hops dan ladder drill icky shuffle on agility and speed in pencak silat athletes. This studi use experimental method with two groups of pretest-posttest design was. Data analysis using quantitative descriptive statistics and $t$ test. The sample consisted of two groups, 10 students were given the ladder drill scissor hops exercise, and 10 students were given the ladder drill icky shuffle. Do exercise for 6 weeks with three exercises per week. Data collected are the 30 meter test to retrieve running speed data and the Illionis Agility Test to retrieve agility data. The results showed the value of the t test agility between groups shows the sig-2 tailed value 0.864>0.05 and the results of the t-speed test show the sig-2 tailed value 0.297>0.05 so that Ho accepted which means both agility and speed have increased but both are not significantly different between the ladder drll scissor hops and the ladder drill icky shuffle.
\end{abstract}

Keywords: Ladder drill, Agility, Speed.

\section{Perbedaan Pengaruh Latihan Ladder Drill Scissor Hops Dan Icky Shuffle Terhadap Peningkatan Kelincahan Dan Kecepatan Pada Atlet Pencak Silat}

\begin{abstract}
ABSTRAK
Penelitian ini bertujuan mencari perbedaan pengaruh latihan ladder drill scissor hops dan ladder drill icky shuffle terhadap peningkatan kelincahan dan kecepatan pada atlet pencak silat. Metode eksperimental dengan two group pretest -posttest design digunakan dalam .penelitian ini. Data dianalisis dengan statistik deskriptif kuantitatif dan uji t. Sampel dibagi menjadi dua kelompok, kelompok kesatu 10 siswa diberi latihan ladder drill scissor hops, dan kelompok kedua 10 siswa diberi latihan ladder drill icky shuffle. Pelaksanaan latihan selama 6 minggu dengan tiga kali latihan perminggu. Instrumen yang digunakan untuk mengumpulkan data yaitu tes akselerasi 30 meter untuk mengambil data kecepatan lari dan Illionis Agility T Test mengambil data kelincahan. Hasil penelitian menunjukkan uji t kelincahan antar kelompok menunjukkan nilai sig-2 tailed $0.864>0.05$ dan hasil uji t kecepatan menunjukkan nilai sig-2 tailed $0.297>0.05$ sehingga Ho diterima yang artinya baik kelincahan dan kecepatan mengalami peningkatan akan tetapi samasama tidak terdapat perbedaan yang signifikan antara latihan ladder drill scissor hops dan latihan ladder drill icky shuffle.
\end{abstract}

Kata kunci: Ladder Drill, Kelincahan, Kecepatan.

Info Artikel

Dikirim

Diterima

Dipublikasikan
: 28 April 2020

: 5 Mei 2020

: 11 Mei 2020
(C) 2020 IKIP BUDI UTOMO MALANG

P-ISSN 2613-9421

E-ISSN 2654-8003

\ Alamat korespondensi: Rojilghufron25@gmail.com

IKIP Budi Utomo Malang, Jl. Simpang Arjuno No.14B, Kauman, Kec. Klojen, Kota Malang, Jawa Timur 65119, Indonesia 


\section{PENDAHULUAN}

Setidaknya ada 4 komponen untuk mencapai prestasi olahraga yang tinggi, yakni Fisik, teknik, taktik dan mental. Adapun komponen fisik yang harus diperhatikan dan dikembangkan (Harsono, 2017) adalah daya tahan (kardiovaskuler), daya tahan kekuatan (strength endurance), kekuatan otot (strength), keletukan (flexibility), kecepatan (speed), kelincahan (agility), dan daya ledak otot (power). Komponen-komponen tersebut sangat diperlukan bagi atlet pencak silat. Karena itu atlet-pelatih berupaya selalu memonitor kondisi fisik atlet melalui tes dan pengukuran kondisi fisik. Selain itu pelatih juga berusaha mencari metode latihan yang efektif untuk meningkatkan kondisi fisik atlet.

Ada beberapa metode latihan yang dapat digunakan untuk mengembangkan kelincahan dan kecepatan. Namun akhir-akhir ini metode latihan ladder sangat populer. Hampir semua pelatih cabang olahraga menggunakan model latihan ladder. Banyak variasi dalam latihan ladder drill menurut (Graham \& Verrigno, 2005) meliputi icky shuffle, crossover shuffle, in out shuffle, scissor hops, lateral high knee dan lainnya. Dari berbagai macam variasi tersebut juga terdapat penjelesan yang berbeda tenteng kefektifan dari berbagai variasi latihan seperti halnya pada (Rahardian, RM, Hariyanto, E, Haryoko 2019) latihan ladder drill model zig-zag hops memberikan pengaruh yang lebih baik dibandingkan latihan ladder drill model lateral terhadap peningkatan kelincahan” (Rahardian, RM, Hariyanto, E, Haryoko 2019), (Tefu, 2019) latihan ladder drill speed run lebih berpengaruh pada kecepatan dan latihan ladder drill in out drill lebih berpengaruh pada kelincahan, hal ini juga di tegaskan dalam penelitian (Fantiro, 2018) bahwa ladder drill crossover memberikan pengaruh kelincahan yang lebih bagus dari latihan ladder drill speed run. Penelitan ini nantinya untuk memberi tahukan bahwasannya bentuk latihan ladder drill scissor hops dan icky shffle tidak terdapat perbedaan yang signifikan dalam hal meningkatkan kelincahan dan kecepatan. Berbeda dari penelitian sebelumnya yang menjelaskan ada perbedaan pengaruh pada bentuk latihan ladder drill yang berbeda.

Akan tetapi pada penelitian ini bentuk variasi latihan ladder drills yang digunakan adalah ladder drill scissor hops dan ladder drill icky shuffle. Banyak 
variasi model latihan ladder. Penelitian ini bertujuan untuk mengetahui perbedaan pengaruh bentuk latihan ladder drill scissor hops dan ladder drill icky shuffle dalam meningkatkan kelincahan dan keepatan namun belum ada penelitian yang menjelaskan tentang keefektifan perbedaan pengaruh ladder drill scissor hops dan ladder drill icky shuffle terhadap peningkatan kelincahan dan kecepatan pada atlet pencak silat. Latihan ini dipilih karena gerakannya menyerupai gerakan serang bela dalam teknik pencak silat. Atlet pencak silat memerlukan kondisi fisik kelincahan dan kecepatan yang tinggi. Banyak yang mengetahui tentang alat latihan ladder drill akan tetapi dilapangan masih banyak sekali orang yang belum menggunakan alat tersebut sebagai sebagai pelatihan fisik.

Lalu apa sebenarnya kondisi fisik kelincahan itu. Kelincahan adalah gerakan anggota tubuh yang dapat mengubah arah dengan cepat dalam menanggapi stimulus. Oleh karena itu definisi ini mencakup komponen ketangkasan dan fisik dari ketangkasan (Robin, KV \& Louis, 2019). Jadi kelincahan adalah gerakan seluruh tubuh yang cepat dengan perubahan kecepatan atau arah secara cepat, efektif dan efisien tanpa mengalami kesulitan. Sedangkan kecepatan menurut (Bompa \& Haff, 2009) adalah ekspresi dari serangkaian keterampilan dan kemampuan yang memungkinkan kecepatan gerak tinggi atau memindahkan seluruh atau sebagian tubuh dengan cepat. Hal ini Senada juga dengan (Sukadiyanto \& Muluk, 2011) bahwa kecepatan merupakan kemampuan otot atau sekelompok otot untuk menjawab rangsang dalam waktu secepat mungkin. Ada berbagai macam bentuk latihan yang dapat meningkatkan kelincahan dan kecepatan diantaranya dengan menggunakan ladder drill, (Adhi \& Himawan Wismanadi, 2018) latihan menggunakan ladder drill dapat meningkatkan kecepatan hal ini dapat digunakan sebagai pertimbangan dalam variasi melatih kecepatan. ladder drill merupakan suatu bentuk latihan yang menyerupai anak tangga, yang sangat baik untuk meningkatkan kecepatan, koordinasi, dan kelincahan kaki secara keseluruahan. Sedangkan menurut pendapat (Dawes \& Roozen, 2012) bahwa "Ladder drills to help athletes develop quick feet, body control, and kinesthetic awareness, as well as improve fundumental movement skill'. yang dimaksud adalah latihan tangga untuk membantu para atlet 
mengembangkan kecepatan kaki, kontrol tubuh, dan kesadaran kinestetik, serta meningkatkan keterampilan dasar.

Ada banyak peneliti yang telah membuktikan pengaruh latihan ladder terhadap kelincahan. (Pawar \& Borkar, 2018) melaporkan bahwa ada peningkatan yang signifikan pada kelincahan pemain kabaddi setelah diberi latihan ladder selama 6 minggu. Assya'bani, K. dan Widodo, A, (2016) Juga melaporkan bahwa terdapat peningkatan kelincahan pada atlet sesudah diberi latihan Ladder drills icky shufle. (Kusuma \& Kardiawan, 2017) menjelaskan bahwasannya terdapat peningkatan kecepatan lari, kelincahan dan kekuatan otot kaki setelah diberikan pelatihan ladder drill. (Chandrakumar \& Ramesh, 2015) berdasarkan hasil penelitian dijelaskan bahwasannya latihan ladder drill dan SAQ secara signifikan dapat meningkatkan kecepatan dan kelincahan pada pemain badminton.

\section{METODE}

Metode eksperimen digunakan untuk menguji berbedaan kedua bentuk latihan ladder drill scissor hops, dengan ladder drill icky shuffle. Desain penelitian ini adalah Non-Randomized Control Group Pretest-Posttest (Maksum, 2012). Sebanyak 20 siswa putri $(n=20)$ direkrut untuk menjadi subjek penelitian ini. Subjek penelitian berasal seluruh siswa yang mengikuti kegiatan ekstra kulikuler pencak silat di MTs Darun Nur yang berjumlah 20 siswa. Subjek dibagi menjadi dua kelompok yang dipilih secara random, kelompok eksperimen ladder drill scissor hops $(\mathrm{n}=10)$ dan kelompok ladder drill icky shuffle $(\mathrm{n}=10)$ Usia Subjek antara 15-17 tahun. Rancangan penelitian eksperimen ini sebagaimana tertera dalam tabel 1.1 barikut:

Tabel 1. Rancangan Penelitian

\begin{tabular}{ccc}
\hline Pretest & Treatment & Posttest \\
\hline $\mathrm{T} 1_{1}$ & $\mathrm{X} 1$ & $\mathrm{~T} 2_{1}$ \\
\hline $\mathrm{T} 1_{2}$ & $\mathrm{X} 2$ & $\mathrm{~T} 2_{2}$ \\
\hline $\mathrm{T} 2_{1}$ & $\mathrm{VS}$ & $\mathrm{T} 2_{2}$ \\
\hline
\end{tabular}

Keterangan :

$\mathrm{T}_{1} \quad$ : Pre test kelompok Ladder Drills Scissor hops

$\mathrm{T}_{2} \quad$ : Pre Test kelompok Ladder Drills Icky Shuffle

$\mathrm{X}_{1} \quad$ : Perlakuan kelompok eksperimen Ladder Drills scissor hops

$\mathrm{X}_{2} \quad$ : Perlakuan kelompok eksperimen Ladder Drills Icky Shuffle

T2 1 : Post test kelompok Ladder Drills Scissor Hops 
$\mathrm{T}_{2} \quad$ : Post test kelompok Ladder Drills Icky Shuffle

Teknik analisis data menggunakan uji t amatan ulang (paired-samples $t$ test) dependent) dan uji t antar kelompok (independent sample t test) (Maksum, 2012). Uji t amatan ulang untuk menguji peningkatan kelincahan dan kecepatan pada 2 kelompok rata-rata pre test dan post test dan uji t antar kelompok untuk menguji perbedaan peningkatan kelincahan dan kecepatan antara kelompok ladder drill scissor hops dan ladder drill icky shuffle. Instrumen yang digunakan untuk mengumpulkan data yaitu tes akselerasi 30 meter untuk mengambil data kecepatan lari dan Illionis Agility T Test mengambil data kelincahan.

\section{HASIL DAN PEMBAHASAN}

Berdasarkan dari analisis data diperoleh hasil, sebagaimana tercantum dalam tabel 1.2 berikut:

Tabel 2. Hasil Uji Paired Sampel t Test

\begin{tabular}{lcccccc}
\hline \multicolumn{1}{c}{ Treatment } & Df & $\begin{array}{c}\text { Mean Pre- } \\
\text { test }\end{array}$ & $\begin{array}{c}\text { Mean } \\
\text { Post-test }\end{array}$ & $\begin{array}{c}\text { Perbedaan } \\
\text { mean }\end{array}$ & t test & $\begin{array}{c}\text { Sig.(2- } \\
\text { tailed) }\end{array}$ \\
\hline $\begin{array}{l}\text { Peningkatan kelincahan } \\
\text { group latihan ladder } \\
\text { drill scissor hops }\end{array}$ & 9 & 22.554 & 20.989 & 1.565 & 4.078 & .003 \\
\hline $\begin{array}{l}\text { Peningkatan kelincahan } \\
\text { group latihan ladder } \\
\text { drill icky shuffle }\end{array}$ & 9 & 23.149 & 21.667 & 1.482 & 5.253 & .001 \\
\hline $\begin{array}{l}\text { Peningkatan kecepatan } \\
\text { group latihan ladder } \\
\text { drill scissor hops }\end{array}$ & 9 & 6.239 & 5.732 & 0.507 & 4.408 & .002 \\
\hline $\begin{array}{l}\text { Peningkatan kecepatan } \\
\text { group latihan ladder } \\
\text { drill icky shuffle }\end{array}$ & 9 & 6.779 & 6.083 & 0.696 & 5.221 & .001 \\
\hline
\end{tabular}

Data kelompok ladder drill scissor hops terhadap kelincahan pada tabel 1.2 menunjukkan bahwa group pemain yang dilatih menggunakan ladder drill scissor hops, diperoleh data rerata pre test kelincahan 22.55 detik sedangkan rerata pos test 20.98 detik, dengan t test 4,078 sig .003.

Data kelompok ladder drill icky shuffle terhadap kelincahan pada tabel 1.2 menunjukkan bahwa rerata pre test kelincahan 23.14 detik dan rerata post test 21.66 detik dengan t test 5.253 dan sig .0.001. Hasil ini senada dengan hasil penelitian 
Bhisaji Pawar \& Borkar (2018), bahwa ada peningkatan yang signifikan pada kinerja kelincahan kelompok eksperimen bila dibandingkan dengan kelompok kontrol.

Data kelompok ladder drill scissor hops terhadap kecepatan menunjukkan bahwa rerata pre test sebesar 6.23 detik, dan rata post test sebesar 5.73 detik dengan t test 4.408 dan sig .002. Data kelompok ladder drill icky shuffle terhadap kecepatan menunjukkan bahwa rerata pre test sebesar 6.77 detik, dan rerata post test sebesar 6.08 detik dengan $\mathrm{t}$ test 5.221 dan sig .001. Sedangkan hasil uji t antar kelompok latihan diperoleh data sebagaimana tercantum dalam tabel 1.3 berikut.

Tabel 3. Hasil Uji Unpaired Sampel t Test

\begin{tabular}{|c|c|c|c|c|c|}
\hline Treatment & df & $\begin{array}{c}\text { Mean } \\
\text { Post-test }\end{array}$ & $\begin{array}{c}\text { Selisi } \\
\text { h }\end{array}$ & t test & $\begin{array}{l}\text { Sig. }(2 \mathrm{t} \\
\text { ailed) }\end{array}$ \\
\hline $\begin{array}{l}\text { Group latihan ladder drill } \\
\text { scissor hops terhadap } \\
\text { kelincahan }\end{array}$ & 9 & 20.989 & 1.56 & 0.864 & 0,05 \\
\hline $\begin{array}{l}\text { Group latihan ladder drill icky } \\
\text { shuffle terhadap kelincahan }\end{array}$ & 9 & 21.667 & & & \\
\hline $\begin{array}{l}\text { Group latihan ladder drill } \\
\text { scissor hops terhadap kecepatan }\end{array}$ & 9 & 5.732 & 1.48 & 0.297 & 0,05 \\
\hline $\begin{array}{l}\text { Group latihan ladder drill icky } \\
\text { shuffle terhadap kecepatan }\end{array}$ & 9 & 6.083 & & & \\
\hline
\end{tabular}

Hasil uji t antara kelompok ladder drill scissor hops dan ladder drill icky shuffle terhadap kelincahan menunjukkan bahwa rerata peningkatan kelincahan pemain pencak silat dengan menggunakan variasi latihan ladder drill Scissor Hops sebesar 1.56 sedangakan ladder drill Icky Shuffle sebesar 1.48. Hal ini menunjukkan ada perbedaan peningkatan kelincahan antara group latihan scissor hops dan latihan icky shuffle, namun tidak signifikan.

Hasil uji rata-rata kelompok latihan scissor hops dan icky shuffle terhadap kecepatan menunjukkan bahwa rata-rata peningkatan kelincahan pemain pencak silat dengan menggunakan latihan Scissor Hops sebesar 0.51 sedangkan group Icky Shuffle sebesar 0.70. Hal ini menunjukkan bahwa ada berbedaan peningkatan latihan ladder scissor hops dan latihan ladder icky shuffle terhadap kecepatan, namun tidah signifikan. Latihan dengan ladder drill icky shuffle lebih efektif dalam meningkatkan kecepatan pemain pencak silat MTs Darun Nur. Hal 
ini sesuai dengan hasil penelitian (Juliyanto, 2016) bahwa latihan ladder dril icky shuffle berpengaruh pada peningkatan kecepatan gerak lari. Sejalan dengan penelitian (Nuryadi \& Firmansyah, 2018) yang melaporkan bahwa latihan ladder drill dapat meningkatkan kecepatan lari 60 meter. Sangat jelas sekali bahwa latihan ladder drill merupakan salah satu bentuk latihan yang efektif dalam meningkatkan kecepatan akan tetapi tidak semua bentuk latihan ladder drill dapat meningkatkan kecepatan seperti halnya pada penelitian (Pelamonia \& Harmono, 2018) menjelaskan bahwa terdapat peningkatan pada latihan ladder drill 90 degree rotation dan ali shuffle terhadap kecepatan akan tetapi peningkatan tersebut tidak signifikan yang berarti pada latihan ladder dril 90 degree rotation dan ali shuffle tidak disarankan untuk melatih kecepatan.

Dalam melatih kelincahan dan kecepatan latihan ladder drill sangat disarankan karena selain menghemat tempat juga banyak variasi dalam bentuk latihan ladder drill tergantung komponen kebutuhan fisik atlet. Berbeda dengan penelitian (Windiar \& Malinda, 2019) pada model latihan 40 yards sprint dan 40 yards backpedal-forward juga dapat meningkat kecepatan dan kelincahan atlet, tetapi latihan tersebut membutukan lahan yang luas. sehingga hal ini menjelaskan bahwa pengembangan dalam latihan kelincahan dan kecepatan bisa digunakan dengan menggunakan alat ladder drill yang mana dapat menhemat tempat dan juga mempunyai banyak variasi dalam latihan sehingga tidak mudah bosan dalam pelatihannya.

\section{SIMPULAN}

Berdasarkan hasil penelitian ditemukan bahwa latihan scissor hops dan icky shuffle dapat meningkatkan kelincahan dan kecepatan atlet pencak silat di MTs Darun Nur. Hal ini ditunjukkan dengan peningkatan rerata kelincahan kelompok latihan scissor hops 1.56 detik dan peningkatan rerata latihan icky shuffle 1.48 detik. Sedangkan dalam kecepatan peningkatan rata-rata kelompok latihan scissor hops sebesar 0.50 dan latihan icky shuffle sebesar 0.69.

Maka pada penelitian ini menunjukkan perbedaan kefektifan latihan scissor hops dan icky shuffle, yang mana pada latihan scissor hops lebih efektif 
dalam meningkatkan kelincahan sedangkan pada latihan icky shuffle lebih efektif dalam hal kecepatan.

\section{DAFTAR RUJUKAN}

Adhi, Y. N., \& Himawan Wismanadi, M. P. (2018). Pengaruh Latihan Ladder Drill Crossover Shuffle Terhadap Peningkatan Kecepatan. Kesehatan Olahraga, 02(07). Jurnal Kesehatan Olahraga, 6(2).

Assya'bani, K., \& Widodo, A. (2016). Pengaruh Latihan Ladder Drills icky Shuffle Terhadap Kelincahan. Kesehatan Olahraga, 05(02), 40-46.

Bompa, tudor o., \& Haff, g. gregory. (2009). Periodization Theory and Methodology of Training (Fifth Edit). Sheridan Books.

Chandrakumar, N., \& Ramesh, C. (2015). Effect of ladder drill and SAQ training on speed and agility among sports club badminton players. International Journal of Applied Research, 1(12), 527-529.

Dawes, J., \& Roozen, M. (2012). Developing Agility and Quickness. Sheridan Books.

Fantiro, F. A. (2018). Perbedaan pengaruh latihan ladder drill speed run dan ladder drill crossover terhadap peningkatan kelincahan (agility) siswa Sekolah Dasar Moh. Hatta Kota Malang. JPOS (Journal Power Of Sports), 1(2), 14-22.

Graham, J., \& Verrigno, V. (2005). Agility and Balance Training (pp. 71-136). United Graphics.

Harsono. (2017). Kepelatihan Olahraga. Bandung: PT Remaja Rosdakarya.

Juliyanto, O. D. (2016). Pengaruh Latihan Ladder Drill Icky Shuffle Terhadap Peningkatan Kecepatan Gerak Jurnal Kesehatan Olahraga, 4(4).

Kusuma, K. C. A., \& Kardiawan, I. K. H. (2017). Effect of Ladder Drill Exercise on Speed, Surrounding, and Power Leg Muscle. Journal of Physical Education, Sport, Health and Recreations, 6(3), 193-196.

Maksum, A. (2012). Metodologi Penelitian Dalam Olahraga. Surabaya: Unesa University Press.

Nuryadi, A., \& Firmansyah, G. (2018). Pengaruh Latihan Ladder Drill Terhadap Kecepatan Lari 60 Meter di Ssekolah Basket LOC Sidoarjo. Jp. jok (Jurnal Pendidikan Jasmani, Olahraga dan Kesehatan), 2(1), 63-69.

Pawar, S. B., \& Borkar, P. (2018). Effect Of Ladder Drills Training In Female Kabaddi Players. Physical Education, Sport and Health, 5(2), 180-184.

Pelamonia, S. P., \& Harmono, B. A. (2018). Pengaruh Pelatihan Ladder Drill 90 Degree Rotation dan Ladder Drill Ali Shuffle Terhadap Peningkatan Daya 
Ledak Otot Tungkai dan Kecepatan. Jp. jok (Jurnal Pendidikan Jasmani, Olahraga dan Kesehatan), 2(1), 20-29.

Rahardian, M. R., Hariyanto, E., \& Hariyoko, H. (2019). Pengaruh Model Latihan Ladder Drill Lateral Dan Zig-Zag Hops Terhadap Peningkatan Kelincahan. Indonesia Journal of Sports and Physical Education, 1(1), 27-33.

Robin, KV, \& Louis, Y. R. (2019). Impact Of Ladder Training On The Agility Performance Of Footballers. 4(1), 779-781.

Sukadiyanto \& Muluk, D. (2011). Pengantar Teori Dan Metodologi Melatih Fisik. Bandung: Lubuk Agung.

Tefu, J. A. (2019). Pengaruh Latihan Ladder drill: Ladder Speed Run dan In Out Drill Terhadap Peningkatan Kecepatan dan Kelincahan. Jendela Olahraga, 4(1), 32-37. https://doi.org/10.26877/jo.v4i1.2986

Windiar, D. B., \& Malinda, K. A. (2019). Pengaruh Latihan 40 Yards Sprint dan 40 Yards Backpedal-Forward Terhadap Kecepatan dan kelincahan. Jp. jok (Jurnal Pendidikan Jasmani, Olahraga dan Kesehatan), 3(1), 71-81. 